\title{
Revista Clínica de Medicina de Familia: Origen y Reflexiones
}

\author{
Jesús López-Torres Hidalgo ${ }^{a}$ \\ a Médico de Familia, Centro de Salud Universitario Zona IV de Albacete. \\ Ex editor de Revista Clínica de Medicina de Familia.
}

Revista Clínica de Medicina de Familia fue fundada en 2005. Por entonces el "saldo vegetativo" que ofrecían las revistas médicas españolas era claramente negativo, es decir, finalizaban su andadura más revistas de las que se originaban en aquellos años ${ }^{1}$. A pesar de ello, quienes contribuimos al nacimiento de la revista considerábamos en aquel momento que se trataba de "una buena idea" y disponíamos del entusiasmo necesario para emprender el camino, sabiendo también que para que una iniciativa prospere y se perpetúe en el tiempo no basta con esto, pues se necesitan además los recursos necesarios para sacar adelante el proyecto. Si bien la mayoría de las iniciativas fracasan al cabo de un par de años, hoy, ocho años después, debemos felicitarnos por la continuidad de Revista Clínica de Medicina de Familia.

Coincidiendo con el VI Congreso de Atención Primaria de Castilla-La Mancha (Toledo, 2005), la revista surgió como publicación oficial de la Sociedad Castellano-Manchega de Medicina de Familia y Comunitaria, dispuesta a abordar la prevención y el tratamiento de los problemas de salud más prevalentes en el ámbito de Atención Primaria, así como otros aspectos clínicos de interés para el médico de familia. Como vehículo de información científica entre estos profesionales, la revista, con una periodicidad cuatrimestral, se ha mantenido hasta ahora gracias al esfuerzo de sus autores, sus lectores y su Comité Editorial. Esta "puerta abierta" a la investigación en Medicina de Familia ha permanecido bien representada hasta ahora en cada portada de la revista por la Puerta de Hierros, símbolo de "apertura" en la ciudad de Albacete cada mes de septiembre.

Fuimos venciendo las dificultades iniciales $y$, no sin esfuerzo por parte del Comité Editorial, los manuscritos comenzaron a llegar, permitiendo completar satisfactoriamente cualquiera de las secciones de la revista. En palabras de García Lorca "con el tiempo el nudo se deshace y la fruta madura...", y además comprendimos que Revista Clínica de Medicina de Familia no sólo permitía el intercambio de información entre los compañeros de Atención Primaria sino que también constituía una excelente oportunidad para que médicos de familia, residentes y otros profesionales pudieran iniciarse en tareas de investigación y consiguieran ver publicados sus primeros trabajos. En los 21 números publicados entre junio de 2005 y febrero de 2012, momento en el que se dio paso a un nuevo Comité Editorial, se publicaron 280 manuscritos ${ }^{2}$, comprobándose cada año un incremento en el número de los mismos y un predominio tanto de artículos originales $(30,7 \%)$ como de casos clínicos (29,6\%). Analizando los contenidos publicados, los aspectos clínicos han representado en dicho periodo un $68,6 \%$ del total, por lo que podemos calificar de bastante adecuado el título de "Revista Clínica...", sin olvidar otros aspectos que han estado notablemente presentes, como los relacionados con la organización y gestión de servicios sanitarios, la investigación, la educación médica - los que abordan problemas sociosanitarios. También una revista "...de Medicina de Familia", ya que las fuentes principales de los manuscritos han sido los centros de salud, las unidades docentes de Medicina Familiar y Comunitaria o las gerencias de Atención Primaria (58,2\%), seguidas a gran distancia de hospitales (18,2\%), universidades $(12,1 \%)$ y otras fuentes $(11,4 \%)$. En la misma línea, el 48,2\% de los primeros firmantes han sido médicos de familia y el $16,8 \%$ residentes de Medicina Familiar y Comunitaria. Merecen ser mencionados los centros de salud que más han contribuido: Zona IV y Zona V-B de Albacete y "Sillería" de Toledo.

El origen de los manuscritos, excesivamente local al principio (en su conjunto el $41,8 \%$ de los 
manuscritos fueron remitidos desde centros de Albacete y el $77,5 \%$ desde centros de Castilla-La Mancha), se fue diversificando progresivamente, llegándose a recibir artículos desde 12 de las 17 comunidades autónomas españolas y desde 5 países iberoamericanos. Decisivas fueron la creación de la página web de la revista y su indexación en los repertorios bibliográficos: Índice Médico Español (IME), Scientific Electronic Library Online (SciELO), Índice Bibliográfico Español de Ciencias de la Salud (IBECS) y Red de Revistas Científicas de América Latina y el Caribe, España y Portugal (REDALYC).

Resulta obvio que Revista Clínica de Medicina de Familia es una publicación modesta, pero también que su progresión ha sido notable y satisfactoria. Sería absurdo, y también un atrevimiento, compararla con cualquiera de las revistas médicas más prestigiosas, aunque seguramente éstas en sus orígenes también atravesaron importantes dificultades. Como buen ejemplo, hace más de dos siglos el cirujano de Boston John Collins Warren (1778-1846), impulsor de la anestesia en la cirugía y fundador del Hospital General de Massachusetts, puso en marcha The New England Journal of Medicine. Pues bien, los primeros 100 ejemplares, en enero de 1812, fueron entregados a caballo ${ }^{3}$, sin embargo hoy, tras haber ejercido una notable influencia en la Medicina, dos millones de personas leen la revista en formato electrónico cada mes y su factor de impacto es superior a 50 . No obstante, a pesar de las enormes diferencias, puedo afirmar que Revista Clínica de Medicina de Familia comparte con The New England Journal of Medicine la idea de que la Ciencia debe guiar los cuidados médicos y que también ha tenido como principal objetivo divulgar información con la mejor calidad posible. En su nueva etapa Revista Clínica de Medicina de Familia deberá mantenerse fiel a estos principios si lo que se pretende es "acortar distancias...".

Desde el primer artículo publicado en 2005, titulado "La investigación biomédica como respuesta a las necesidades de la sociedad" " y escrito por el primer editor, la labor editorial de Revista Clínica de Medicina de Familia ha requerido bastante esfuerzo y bastante dedicación, permitiendo a sus responsables descubrir la complejidad del proceso. El editor, intermediario de autores, revisores y lectores, ha asumido en estos años sus responsabilidades con cada uno de ellos y ha intentando mantener la integridad de la revista, estableciendo la política editorial y administrando el proceso de revisión de artículos de forma correcta, entre otras tareas.

Varias son las razones para la continuidad de Revista Clínica de Medicina de Familia. A la mayoría de los médicos de familia españoles les resulta más útil leer artículos en español que en inglés ${ }^{5}$ y estas preferencias deberán ser tenidas en cuenta en el futuro por parte de los editores de nuestro país, aprovechando la ventaja de pertenecer a un ámbito idiomático extenso, lamentablemente con una notable escasez de publicaciones médicas. Suprimidas las barreras con el idioma, parece razonable pensar en un mejor aprovechamiento de la información científica. Por otra parte, para nuestros editores los intereses de los médicos "lectores" deberán ser tan importantes como los de los médicos "investigadores". Aunque el número de estos últimos sea inferior al de los primeros, también los médicos de familia publican mayoritariamente sus trabajos en revistas españolas ${ }^{7}$. Al respecto, en la investigación que se realiza en Medicina de Familia, la producción científica de Castilla-La Mancha ha alcanzado en los últimos años un nivel muy satisfactorio en el contexto nacional, tanto en calidad como en cantidad. Teniendo en cuenta las anteriores circunstancias, Revista Clínica de Medicina de Familia puede llegar a ser una opción muy adecuada en el panorama actual de las revistas médicas españolas.

Sería deseable a partir de ahora, entre otros aspectos, volver a plantear la misión y los objetivos de la revista, alcanzar una mayor periodicidad, al menos bimestral o trimestral, trabajar activamente para disponer de una mayor financiación, agilizar el proceso editorial y, especialmente importante, lograr su inclusión en Medline. Para lograrlo, yo animo al nuevo Comité Editorial a "seguir remando" en la dirección adecuada.

\section{BIBLIOGRAFÍA}

1. Abad García MF, González Teruel A, Martínez Catalán C. Características de las revistas médicas españolas. 2004. El profesional de la información. 2005; 14:380-90.

2. López-Torres Hidalgo J. Revisión histórica de Revista Clínica de Medicina de Familia. Conferencia inaugural. 
Jornadas de Investigación en Atención Primaria de Castilla-La Mancha, Ciudad Real, 21-22 de junio de 2013.

3. Marchione M. New England Journal: 200 años de historia de la medicina. Disponible en: http://www.azcentral. com/lavoz/spanish/health/articles/health_14926.html. [Consultado el 18/07/2013].

4. López-Torres Hidalgo J. La Investigación Biomédica como respuesta a las necesidades de la Sociedad. Revista Clínica de Medicina de Familia. 2005; 1:6-8.

5. González de Dios J, Flores Canoura A, Jiménez Villa J, Gutiérrez Fuentes JA. Qué revistas médicas españolas leen y cómo se informan los médicos de atención primaria. Atención Primaria. 2011; 43:629-37.

6. López-Torres Hidalgo J. Hábitos de lectura de revistas científicas en los médicos de Atención Primaria. Atención Primaria. 2011; 43:636-7.

7. Violán Fors C, Grandes Odriozola G, Zabaleta-del-Olmo E, Gavilán Moral E. La investigación en atención primaria como área de conocimiento. Informe SESPAS 2012. Gaceta Sanitaria. 2012; 26:76-81. 